\title{
A Short History of the Evolution of the Climate Smart Agriculture Approach and Its Links to Climate Change and Sustainable Agriculture Debates
}

\author{
Leslie Lipper and David Zilberman
}

\begin{abstract}
Climate Smart Agriculture (CSA) is an approach to guide the management of agriculture in the era of climate change. The concept was first launched in 2009, and since then has been reshaped through inputs and interactions of multiple stakeholders involved in developing and implementing the concept. CSA aims to provide globally applicable principles on managing agriculture for food security under climate change that could provide a basis for policy support and recommendations by multilateral organizations, such as UN's FAO. The major features of the CSA approach were developed in response to limitations in the international climate policy arena in the understanding of agriculture's role in food security and its potential for capturing synergies between adaptation and mitigation. Recent controversies which have arisen over CSA are rooted in longstanding debates in both the climate and sustainable agricultural development policy spheres. These include the role of developing countries, and specifically their agricultural sectors, in reducing global GHG emissions, as well as the choice of technologies which may best promote sustainable forms of agriculture. Since the term 'CSA' was widely adopted before the development of a formal conceptual frame and tools to implement the approach, there has been considerable variation in meanings applied to the term, which also contributed to controversies. As the body of work on the concept, methods, tools and applications of the CSA approach expands, it is becoming clearer what it can offer. Ultimately, CSA's utility will be judeged by its effectiveness in integrating climate change response into sustainable agricultural development strategies on the ground.
\end{abstract}

\footnotetext{
L. Lipper $(\bowtie)$

ISPC-CGIAR, Rome, Italy

e-mail: leslie.lipper@fao.org

D. Zilberman

Department of Agriculture and Resource Economics, University of California Berkeley,

Berkeley, CA, USA

e-mail: zilber11@berkeley.edu
} 


\section{Introduction}

Climate Smart Agriculture (CSA) is an approach to guide the management of agriculture in the era of climate change. The concept was first launched in 2009, and since then has been reshaped through inputs and interactions of multiple stakeholders involved in developing and implementing the concept. CSA aims to provide globally applicable principles on managing agriculture for food security under climate change that could provide a basis for policy support and recommendations by multilateral organizations, such as UN's FAO. The major features of the CSA approach were developed in response to debates and controversies in climate change and agricultural policy for sustainable development.

The purpose of this paper is to give an overview of the evolution of CSA, introduce its major components, and summarize the key debates associated with it within the context of climate change and agricultural policy debates The first section provides an overview of international climate change policy followed by an introduction and analysis of CSA and its history. This is then followed by a discussion of three broad controversies related to CSA, namely the role of mitigation, the relationship of CSA to sustainable agriculture, and way biotechnology is treated in the CSA approach.

\subsection{The Evolution of Climate Change Policy}

To put CSA and its controversies in context, it is necessary to understand the evolution of global climate change policies over recent years. We use the framing of Gupta (2010), who traces the history of international climate change policy, from 1979 to 2010. He distinguishes between five phases of evolution. He refers to the pre-1990 phase as the period of framing the problem, beginning with the World Climate Conference in 1979 and including the establishment of the International Panel on Climate Change (IPCC) in 1988. The main focus of global climate change policy during this period was the need for global action to stabilize greenhouse gas (GHG) emissions, to be supported and guided by a globally cooperative framework for undertaking scientific research in the form of the IPCC, and with the understanding that developed and developing countries would bear different responsibilities to mitigate climate change. Because of the high uncertainty associated with climate change, a precautionary approach to climate change policy was adopted. This implies the need to take preventive action even before full certainty about human-induced climate change was obtained, and secondly, to emphasize no-regrets actions that would be valuable even in the absence of climate change. The publication of the Bruntland Commission Report on Sustainable Development in 1987 (WCED 1987) also led to the realization of the links between climate change and sustainable development and the benefits of considering them in an integrated fashion. 
During the second period of international climate policy between 1991 and 1996, the initial articulation of a global policy framework was introduced, signified by the Rio Convention in 1992 and the adoption of Agenda 21. An important outcome of the Rio Conventions was the establishment of the UN Framework Convention on Climate Change (UNFCCC) which entered into force on 21 March 1994. The ultimate aim of the convention is preventing "dangerous" human interference with the climate system. Article 2 of the convention says this objective should achieved while ensuring that "food production is not threatened". There was much debate on equity and the principle of common but differentiated responsibilities. ${ }^{1}$

Developed countries were assumed to bear much of the responsibility for both causing and reducing GHG emissions. However their response could also include helping developing countries pay for mitigation actions in the developing world. As the policy formation process moved forward, countries began to form coalitions around common interests. For example, small island nations formed one coalition, as did the G77, representing a block of 130 developing countries. Among the developed nations there was clear difference between the EU and the US and furthermore, the division grew between the EU and non-EU nations. Civil society organizations became a major player in the climate change debate with a major division between the northern organizations pursuing environmental and the southern organizations emphasizing development objectives.

The period between 1997 and 2001 saw the emergence of the first global agreement: the Kyoto Protocol. The Protocol emphasized comprehensive targets for GHG reduction in terms of $\mathrm{CO} 2$ equivalence rather than individual GHGs. Developed countries were assigned different GHG reduction targets and there was emphasis on flexibility in achieving these via mechanisms including emission trading, joint fulfillment and implementation (countries could form a bloc to share responsibilities to meet their joint targets). There was also recognition of the importance of financial mechanisms to promote the implementation of the agreements. The clean development mechanisms (CDM) was established, which allowed developed countries to use financial incentives to finance GHG emission reductions in developing countries and then use the credits to meet their own targets.

The establishment of the CDM provided a basis for expanding the use of payment for ecosystem services to meet GHG reduction targets. One important category of actions for emissions reductions highly relevant to agricultural development is that of sequestering carbon in soils and forestry. Many opportunities for agricultural related carbon sequestration were identified through improved soil manage-

\footnotetext{
${ }^{1}$ The Rio Declaration states: "In view of the different contributions to global environmental degradation, States have common but differentiated responsibilities. The developed countries acknowledge the responsibility that they bear in the international pursuit of sustainable development in view of the pressures their societies place on the global environment and of the technologies and financial resources they command."

Similar language exists in the Framework Convention on Climate Change; parties should act to protect the climate system "on the basis of equality and in accordance with their common but differentiated responsibilities and respective capabilities." http://cisdl.org/public/docs/news/brief_ common.pdf.
} 
ment and forestry (McCarl and Schneider 2001). One of the challenges of implementing the Kyoto Protocol (KP) was the need for reliable and cost-effective mechanisms for carbon accounting, monitoring and validation which proved particularly difficult in the case of carbon sequestration. The issue of soil carbon inclusion was hotly debated in the discussions on establishing the CDM (Post et al. 2001; Ringius 2002).

The US, Canada, Brazil, and other countries advocated for the inclusion of soil carbon sequestration as part of the Protocol and developed mechanisms to improve its accounting (Paustian et al. 2004). Lal (2004) argued that payment for carbon sequestration could provide farmers, especially in developing countries, with significant supplementary income. However the EU and others were against its inclusion and ultimately the decision was taken to exclude this category from the international carbon offset markets.

Even more importantly, the global significance of the Kyoto Protocol suffered with the US withdrawl from it in 2001, since the two biggest carbon emitters (US and China) were not a part of it. Nevertheless, the Protocol provided a foundation for international collaboration and established many principles for future policy implementation.

The period between 2002 and 2007 saw a retreat from a global agreement to many bi- and multi-laterial agreements, many of which were initiated by the U.S. The period was characterized by competition for leadership among countries regarding climate change policy strategies. While the EU continued to push for extension and expansion of the Kyoto Protocol, the U.S. emphasized multi-lateral agreements. In particular, the Asia-Pacific Partnership on Clean Development and Climate, signed in 2005 (and concluded, with many of its projects canceled, in 2011) emphasized the desire to introduce technological solutions to reduce greenhouse gases (GHG) through, for example, collaboration on R\&D aiming towards 'clean coal' (Tan 2010).

The growing emphasis on government support to pursue alternative energy sources also had significant impact on agriculture, especially with the introduction of biofuel policies in much of the world (U.S., Brazil, EU and many other countries). While GHG reduction was one justification for the subsidization of biofuels, perhaps more important was the need to combat rising energy prices, to improve the balance of trade, and to increase the income of the agricultural sector (Zilberman et al. 2014). The increase in the price of food in 2008 as well as the concern about indirect land use led to the curtailment of biofuel policies, but some studies (Huang et al. 2012) found that biofuels can be beneficial for the poor, as long as mechanisms exist to protect vulnerable populations against extreme price shocks. Since national governments were not able to initiate potent global climate change actions during the period, subnational entities like U.S. states and Canadian provinces have established their own climate change programs. Both national and provincial plans have significantly impacted agriculture by introducing demand for biofuel and biomass as well as subsidizing carbon sequestration activities.

The final period of climate policy evolution considered by Gupta (2010) is the financial crisis period (from 2008 and on). In this time period the UNFCCC has 
moved away from a system where mitigation actions were solely the responsibility of rich countries, to one where mitigation actions in developing countries are now being articulated as part of national policy processes to meet the nation's own mitigation aspirations. The policy and financing issues are significantly different in this context, compared with the situation when developing countries were only participating in greenhouse gas reductions on behalf of rich countries, in the form of a carbon offset.

The main issue on the international climate policy agenda for the UNFCCC COP 15 negotiation held in Copenhagen in 2009 was agreement on a global climate treaty which would lay out responsibilities for reducing emissions. Although COP 15 failed to achieve a global climate agreement, it did produce the "Copenhagen Accord" which called for developing countries to develop mitigation targets to 2020 and included financing commitments of $\$ 100$ billion/year by 2020 as well as $\$ 30$ billion for urgent actions up to 2012. In the following year at COP 16, the Green Climate Fund was established as an operating entity of the Financial Mechanism of the UNFCCC to support projects, programmes, policies and other activities in developing countries. Developing countries - including both emerging and least developed countries - have articulated mitigation actions through Nationally Appropriate Mitigation Actions (NAMAs) (result of COP 18 2011), as well as more recently through their Intended Nationally Determined Contributions (INDCs).

It is also important to note that during this period, CDM operations had expanded considerably, with new methodologies and accounting procedures accompanying the expansion. At the same time the volume and value in the voluntary (e.g. non-compliance) carbon offset markets, which generally does allow for the inclusion of agricultural soil carbon, also expanded rapidly, although still only representing a small percentage of the value of the trading in compliance markets (Hamrick and Goldstein 2016) Opposition to soil carbon credits in the context of developing country agriculture was raised by civil society actors. This opposition was based on the argument that soil carbon offsets were a means of putting the mitigation burden on low income developing country farmers and that farmers were unlikely to see any benefit from participating in such markets, but rather could be exposed to losing rights to their land (Action Aid 2011).

In the most recent period of climate policy development, there is a growing realization that significant impacts of climate change are already being felt, and are likely to continue and deepen. The Paris Agreement reached at the 21st Conference of Parties of the UNFCCC in 2015 signifies an increased global commitment to address climate change, as countries agreed to establish legally binding constraints on GHG emissions that aim to contain average global temperature rise by the use of a mixed market approach that induces both introduction of clean energy and conservation (Cooper 2016). All parties recognize the urgency of establishing adaptation strategies, especially to protect the poor and the vulnerable. As of 31 March 2016, 188 countries had submitted "Intended Nationally Determined Contributions" (INDCs) to the UNFCCC which includes statements of intended actions for mitigation as well as adaptation. More than $90 \%$ of the countries explicitly include agriculture in their mitigation and adaptation plans, with a particularly strong focus 
amongst least developed countries (LDCs) (FAO 2016). Adaptation in the agriculture sector is given high priority, and mitigation from agriculture, including sequestration is also quite prominent in the submissions. Thus the importance of considering adaptation and mitigation together and capturing the potential synergies between them is more important than ever. The potential of the CSA approach for supporting this is also increasingly recognized; 31 of the INDCs explicitly mention CSA in the context of seeking joint poverty reduction and environmental benefits (FAO 2016).

\section{Overview of CSA}

The CSA concept emerged at a moment in time of considerable controversy around the concept and approaches to sustainable agricultural development, and when the specificities of agriculture and its role in food security were not well articulated in the climate change policy process. The former was clearly reflected in the debates and controversies of the development of the International Assessment of Knowledge, Science 2009) Technology for Development (IAASTD) which ran from 2003 to 2008 (Scoones 2009). The main arguments in this fora centered around the role of top-down expert assessments versus local participatory approaches to knowledge generation, as well as the role of biotechnology and specifically transgenic crops in sustainable development. In the global climate change policy arena, agriculture's key role in food security was not clearly articulated and the consideration of adaptation and mitigation in two separate negotiation streams limited capacity to build synergies between them.

The first articulation of the CSA concept was presented in the 2009 FAO report entitled "Food Security and Agricultural Mitigation in Developing Countries: Options for Capturing Synergies, which was launched at the Barcelona Climate Change workshop held in November of that year. In 2010, the FAO paper entitled "Climate-Smart" Agriculture, Policies, Practices and Financing for Food Security, Adaptation and Mitigation" was released as a background paper for the Hague Conference on Agriculture, Food Security and Climate Change held in October of that year (FAO 2010). The conference was organized as a follow up to the Shared Vision Statement agreed at the Seventeenth Session of the Commission on Sustainable Development (CSD-17) in May 2009 and to further develop the agriculture, food security and climate change agenda.

These first expressions of the climate smart agriculture concept argue that the agricultural sector is key to climate change response, not only because of its high vulnerability to climate change effects, but also because it is a main contributor to the problem. It also argued that sustainable transformation of the agricultural sector is key to achieving food security, and thus it is essential to frame climate change responses within this priority. Analysis of the state of knowledge on the adaptation, mitigation and food security benefits of a range of agricultural practices, as well as 
their potential tradeoffs was given as well (e.g. see table 2.2 of the 2009 report as well as FAO 2010). Finally these reports focussed on one of the key issues that arose in CSD-17 discussions - how to finance the transformative changes needed. The CSA work focused on the potential for linking the emerging and potentially huge new sources of climate finance - including but not limited to carbon markets - to support the transition to sustainable agriculture. However, important barriers such as high transactions costs for smallholder agricultural producers to access and benefit from climate finance were clearly identified as major issues (FAO 2011).

The CSA concept sparked considerable attention and debate in international and national agricultural and climate change policy arenas, and it was quickly taken up as a rallying point for mobilizing actions on climate change and agriculture. In the wake of the Hague conference, two parallel global processes related to policy and science of CSA were established. The policy process involved follow up conferences in 2012 in Hanoi Vietnam and 2014 in Johannesburg South Africa. The global CSA science process was initiated with a global CSA science conference at Wageningen in 2011, with subsequent CSA science conferences held at University of California at Davis in 2013 and at CIRAD Montpelier in 2015. One of the main outcomes of these processes was the proposal to establish a global alliance on climate smart agriculture (GACSA) which would bridge the policy and science aspects by focussing on three key action areas: (1) knowledge; (2) enabling environment and (3) investments.

After considerable debate, the GACSA was launched in September 2014 at the UN Climate Summit. Memberships in GACSA may include governments, civil society member/non-government organizations, farmers, fishers and forester organizations, intergovernmental organization (including UN entities), research/extension/education organizations, financing institutions and private sector organizations. As of January 2016 the GACSA has 122 members, including 22 countries.

CSA developments were not only at international level however, with CSA projects initiated at country and regional levels, generally in partnership with international organizations such as FAO, World Bank, local and international NGOs and the Climate Change and Food Security program of the CGIAR.

The rapid and widespread uptake of the CSA concept took place in advance of a clearly defined methodology and definition of CSA, and thus differences in meanings and application of the concept have arisen, and given rise to controversies, which further clarification and development of the CSA concept could ostensibly resolve. However much of the controversy around the CSA concept is related to more fundamental disagreements in global policy debates on climate change and sustainable agriculture. 


\section{Key Features and Evolution of the CSA Concept}

One of the main features of the CSA concept is that it calls for meeting three objectives: sustainably increasing food security through increases in productivity and incomes, building resilience and adapting to climate change, and reducing greenhouse gas emissions compared to a business as usual or baseline scenario.

From its inception, recognition of possible trade-offs between the three objectives, and the potential to increase synergies amongst them through policies, institutions and financing was a key feature of the CSA concept (FAO 2009). The need for locally specific solutions was also an important component. A general framework for assessing trade-offs and synergies was provided in FAO (2009, p. 25), along with several examples of sustainable land management practices and "modern" inputs. However, no specific guidance was provided on how to define a CSA practice, or prioritize amongst objectives, to develop the site specific solutions. A clear conceptual framing of the link between sustainable agriculture and CSA was also missing, hindered by the complexity of tying together the three main objectives. The lack of a clear methodology together with a rapid uptake of the concept resulted in considerably variability in the use of the term and confusion, which in turn has been a major source of controversy around the concept.

By the second global CSA policy conference held in Hanoi in 2012, the beginnings of a CSA methodology and principles were emerging. A CSA methodology presented in one of the background papers to the conference consisted of three major elements included: (1) building a relevant evidence base for assessing tradeoffs and synergies amongst the three main objectives, (2) creating an enabling policy environment that required coordination of climate change and agricultural policies and (3) guiding investments and linking to climate finance. The methodology was based on lessons learned from a CSA project funded by the EC in 2010 and jointly implemented by FAO and three partner countries. As such, it focussed on national level actions; e.g. building evidence on climate impacts and vulnerabilities for the agricultural sector at country level; analysing the effectiveness of varying actions on productivity and incomes and their resilience to site specific climate shocks, and their effects on reducing emissions compared to a business as usual agricultural growth path for the country. Enhanced coordination between national climate change and agricultural policies and strategies is key to creating an enabling policy environment, while analysis of the marginal abatement costs of nationally appropriate mitigation actions gives a clear indication of where potential synergies between the three CSA objectives can best be obtained, and the potential of using mitigation finance to support them.

The Climate Smart Agriculture sourcebook, which was a joint effort of several international organizations, came out in 2013 and provided principles for defining CSA practices as well as conceptual links to sustainable agriculture processes and a wide range of examples from livestock, cropping, fishery and forestry sectors (FAO 2013). The first chapter of the sourcebook lays out two major principles defining CSA practices: (1) increasing resource use efficiency in agricultural systems and (2) 
enhancing the resilience of agricultural systems and the people who depend upon them. Resource use efficiency is a key component of sustainable agricultural intensification strategies. By using resources such as nitrogen fertilizer, feed for livestock, land and water more efficiently, the net return to farmers and thus incomes increase, while pressure on scarce resources and emissions per unit produced are reduced. Increasing resilience involves reducing vulnerability as well as enhancing adaptive capacity. CSA strategies require that resilience and resource use efficiency are pursued together, although specific technologies and institutional arrangements may affect only one or the other. Rather, efficiency and resilience need to be considered in an overall systems perspective that considers different spatial and temporal scales. The importance of ecosystem services provided through for example, improved soil management, agro-biodiversity and landscape management, in achieving resource use efficiency and resilience is also a major tenet of CSA approaches outlined in the sourcebook.

The CSA methodology and principles were further defined through a consultative process involving representatives from a broad spectrum, including international organizations such as FAO, CCAFS and World Bank, national agricultural and climate change policy-makers, academics, and civil society. This consultative process resulted in the publication of a perspectives piece in Nature Climate Change in 2014 that reaffirmed the key components of a CSA methodology, but also addressed some of the emerging controversies associated with the concept (Lipper et al. 2014). One of these was a response to the heavy emphasis on exante identification of farm level practices that could meet all three CSA objectives. The paper argued that CSA did not imply that every practice in every field would have to contribute to food security, adaptation and mitigation, but that meeting these objectives should be considered at broader spatial and temporal scales. It also highlighted the controversy around mitigation in developing countries.

More recently, the World Bank and the CCAFS program have launched a set of "country CSA profiles". ${ }^{2}$ These provide critical stocktaking of ongoing and promising practices for the future, and of institutional and financial enablers for CSA adoption. The profiles provide information on CSA terminology and how to contextualize it under different country conditions. The knowledge product is also a methodology for assessing a baseline on climate smart agriculture at the country level (both national and sub-national) that can guide climate smart development.

The CSA concept and methods were developed by international technical agencies, including FAO, the World Bank, the Climate Change and Food Security Programme of the CGIAR. As such, the concept was built to provide a framework for formulating and taking actions to respond to climate change in agriculture that was broad enough to encompass a wide spectrum of political and economic approaches to managing agriculture. In this way, the concept could be relevant to the wide range of clients served by international agencies and adapted to their specific needs and circumstances. At the same time however, the generality of the

\footnotetext{
${ }^{2} \mathrm{http}: / /$ sdwebx.worldbank.org/climateportal/index.cfm?page=climate_agriculture_profiles.
} 
concept has led to multiple interpretations of its core meaning and thus some confusion and controversy. In the next section we look more closely at the most prominent of these.

\section{CSA Controversies in the Broader Policy Context}

\subsection{The Role of Mitigation and Carbon Finance in CSA}

One of the main criticisms of the CSA approach has been that it prioritizes mitigation over food security and adaptation, and it mandates a link to carbon offset markets (Action Aid 2011, Neufeldt et al. 2013). By explicitly calling attention to the potential of agricultural transformation to generate mitigation benefits, and actively pursuing links to mitigation finance, the CSA approach raised suspicions that it was a means of pushing the mitigation burden on the world's poorest people (Action Aid 2010). The argument was made that CSA advocated pushing carbon offsets for soil carbon sequestration on poor farmers, and this would shift the burden of reducing greenhouse gas emissions from rich, industrialized countries who had actually created the problem, to poor developing countries that already are facing the biggest burden in adapting to climate change. This argument is rooted in controversies over soil carbon sequestration and the role of developing countries in mitigation in the global climate policy debate (see previous section) as well as misconceptions of the framing of climate finance in CSA.

Before discussing misconceptions and policy debates, it is useful to understand the impetus for connecting mitigation finance to agricultural development. In 2008 the fourth assessment report of the IPCC was released. The report included a detailed analysis of the state of knowledge at the time on the technical and economic potential of mitigation from agriculture (Smith et al. 2008). They found an estimated global economic mitigation potential for 2030 from agriculture of 1500 1600, 2500-2700, and 4000-4300 MtCO2-eq/year at carbon prices of up to 20, 50 and $100 \mathrm{US} \$ / \mathrm{tCO} 2-\mathrm{eq}$. The activities with highest economic potential were restoring cultivated organic soils, cropland management, grazing land management, restoration of degraded lands, rice management and livestock. Sequestration of carbon in agricultural soils is a key feature of most of these practices. Within each of these categories the actions analysed had high correspondence with actions promoted for sustainable agriculture, e.g. crop rotation, minimum tillage, nutrient use efficiency, feed efficiency. This analysis from the leading science body on climate change indicated the potential to capture huge synergies between mitigation and sustainable agricultural development.

At the same time, the rapid growth in the development of international carbon offset markets represented a major new and potentially huge source of finance to sup- 
port sustainable agricultural activities with mitigation co-benefits. At the time of the launching of the CSA concept, the valuation of global carbon markets was \$141 billion, composed principally of the clean development mechanism of the Kyoto Protocol and the European ETS system (World Bank 2011). However, as noted in the section on climate policy above, neither of these major financing mechanisms allowed soil carbon sequestration from agricultural practice change as a source of mitigation.

Outside of the formal carbon markets, an alternative voluntary market for carbon offsets was springing up, including projects sponsored by the World Bank Biocarbon Fund, NGOs in developed and developing countries, as well as some regional exchanges. The Chicago Climate Exchange which developed a protocol for soil carbon offsets from reduced tillage and improved pasture management (FAO 2012). However the financing flows through these voluntary markets was miniscule compared with those of the formal carbon markets (FAO 2012).

Essentially, there was very little demand for carbon offsets from soil carbon sequestration from developing country farmers due to their exclusion from the major carbon financing mechanisms. However the question of whether or not they should be allowed in order to open the doors to new financing that could generate both mitigation and development outcomes was an important thrust of early CSA work. If the barrier to accessing a significant new source of financing was simply a lack of good research on how much soil could be sequestered from changes in developing country farming systems, then surely the response should be developing a research agenda to provide the needed science. However as research into the potential of carbon offsets as a source of finance for developing country farmers proceeded, it became clear that issues of weak institutional capacity in developing countries was a more serious barrier. In particular, the rights of people with unclear and informal systems of land tenure to reap carbon benefits was very problematic Leach \& Scoones 2015). Experience with payment for environmental service programs, and particularly the REDD+ process had indicated this was a particularly difficult issue to address, but very commonly found. The REDD+ experience indicated that there was indeed potential for poor farmers and land managers with insecure title to land to be dispossesed through the implementation of a REDD+ program, but that there was also potential for stimulating improvements in tenure systems through the impetus of such programs (Larson et al. 2013). Ultimately, it was well recognized that weak and inequitable institutions were a key barrier to making carbon finance work for small and poor farmers, and thus greater attention should be given to linking international public sources of finance such as the Global Environment Fund to support climate smart agriculture (FAO 2013). At the same time, major shifts in the international climate policy negotiations reduced the importance of international carbon offset markets as the main source of climate finance. The newly reconfigured international climate policy regime with its emphasis on nationally determined contributions to mitigation and adaptation and the prominence 
of agriculture in the contributions from developing countries has created interest in the capacity of agricultural mitigation sources to contribute to developing country's own nationally determined contributions. It also implies a greater need for an approach that can identify how mitigation can be integrated into agricultural transformation strategies without compromising food security, which is of course a major focus of CSA.

To summarize, a major thrust of CSA is building the enabling conditions for a major transformation in agriculture, and developing adequate financing streams adapted to the specific conditions of agriculture is important in this regard. At the time of the launching of the CSA concept, the international carbon offset markets were the largest source of climate finance and thus much attention initially was given to its potential for supporting agricultural transformation in developing countries. Due to the problems with linking carbon finance to smallholder agriculture countries, together with the emergence of new funds for supporting mitigation actions on the part of developing countries in recent years, the emphasis of CSA has shifted away from carbon markets to international public climate finance such as the Green Climate Fund and the Global Environmental Facility. Given the high importance of agriculture in the national expressions of mitigation actions on the part of developing countries, the importance of identifying mitigation actions that are synergistic with food security and adaptation and building financing mechanisms to support them is of greater importance than ever.

\section{CSA and Sustainable Agriculture}

Another major criticism of CSA has been the lack of clear principles by which to define a CSA practice, and thus concerns that the concept and branding could to be used to advance non-sustainable and non-desirable forms of agricultural development. This debate was fuelled by the mistaken notion that CSA was essentially a proposal for a new type of agricultural practice, giving rise to concerns directly related to ongoing and fierce debates about technologies for sustainable agriculture.

CSA is not intended to provide a new set of sustainability principles, but rather a means of integrating the specificities of adaptation and mitigation into sustainable agricultural development policies, programs and investments. CSA strategies and practices then should adhere to the principles that underpin sustainable agriculture and food systems. Recently FAO published a new set of guidelines and approach to achieving sustainable agriculture and food systems (SFA) as ones which meet the following criteria: (1) improving the efficiency of resource use, (2) conserving, protecting and enhancing natural resources, (3) protecting and improving rural livelihoods, (4) enhancing resilience of people, ecosystems and communities and (5) responsible and effective governance mechanisms. 
Of course, these principles are very broad and do not mandate any specific balance or weighting between them in terms of defining a sustainable technology. Nonetheless, the links between the sustainability principles and CSA can be seen. Increasing resilience, conservation and protection of natural resources and increasing resource use efficiency are key components of adaption and mitigation. Protecting and improving rural livelihoods is closely related to the CSA objective of sustainably increasing productivity and incomes. A major thrust of CSA is improvement of climate change and agricultural governance through better coordination and institutional strengthening.

With its emphasis on assessing trade-offs and synergies between its three main objectives, as well as the barriers to adoption, CSA actually addresses one of the most essential issues in sustainable agriculture: what will it take to actually achieve a large scale transformation? The emphasis on explicitly identifying trade-offs in the CSA approach is a reaction to the lack of such consideration in many of the sustainable agricultural approaches which focus only on the benefits obtainable, ignoring costs and barriers. The result has been disappointly low adoption of sustainable agricultural techniques, despite decades of efforts and funds to support them. In the end it is the farmers, fishers, livestock keepers and forest managers that are assigning weights to environmental, social and economic criteria through the decisions they make on how to manage their production systems. However the tradeoffs they face between the objectives are determined by the institutional environment they operate under. For example, sustainable land management techniques such as land restoration or agroforestry can take some years to generate benefits, and they require up-front investments and can involve reductions in income during the initial phase. While over a 20 year time frame such actions can result in higher economic, environmental and social benefits, in the initial phases there are significant tradeoffs between them. This is essential to understanding how to effectively induce transformative change - and it has all too often been ignored in the literature on sustainable agricultural development.

A key issue in the debate on technologies for sustainable agricultural growth focuses on the relationship between natural capital inputs (e.g. ecosystem services such as soil quality or genetic diversity) and manufactured capital inputs (inorganic fertilizer, machinery, improved seed) in an agricultural production system. This debate is rooted in a reaction to the great push in capital inputs (improved seed and inorganic fertilizers) which began in the 1960s, which to a large extent built upon a model of substituting manufactured capital inputs for natural capital; e.g. inorganic fertilizer use could substitute for soil quality, or pesticides for genetic diversity (Tilman et al 2002; IAASTD 2009). Particularly in initial phases, increasing manufactured capital inputs to agricultural production systems was the main thrust of this model of development, although in later phases, the focus has shifted in most cases to increasing the efficiency of manufactured capital inputs (FAO 2012). While the results in terms of production increases have been dramatic, these positive results have been accompanied by high rates of natural resource depletion and degradation, as well as negative environmental impacts on land, air and water (Tilman et al. 2002, 
IAASTD 2009). The social impacts have been the subject of much debate. On the one hand the expansion of food production and lowering of food prices a major benefit to the consumers, particularly the poor (Pingali 2012). On the other hand, the model of a top down technology delivery focussed primarily on favorable production areas, excluded many of the poorest from its benefits.

Sustainable agriculture is part of the larger concept of sustainable development that according to the Brundtland Commission is a development strategy that aims to ensure that future generations would not be worse off compared to the present generation. Sustainable development contains economic, social, and environmental elements, but in principle has limited restrictions on technology, per se, and the use of technologies are judged based on their impacts. Zilberman (2014) argues that one of the major features of sustainable development is the emphasis on conservation technologies that enhance input use efficiency and reduce pollution, introduction of strategies that include resilience and ability to withstand environmental risk, adoption of recycling technologies, and transition from non-renewable to renewable technologies. Renewable technologies include both energy production using solar and wind as well as extension of the bioeconomy, which relies on biological processes to produce food, fuel, and fine chemicals. This approach to sustainable development that allows some substitution among resources and encourages production systems that enhance human welfare subject to constraints should have bearing on the definition of CSA.

The CSA approach is criticized by some advocates of alternative development models, because it does not explicitly exclude the use of manufactured capital inputs and while incorporating participatory and bottom up approaches, it also allows for integration of science-based technology transfers. The CSA literature does however explicitly call for enhancing the complementarity between ecosystem services and manufactured capital, such as improving soil quality to enhance the productivity gains from inorganic fertilizer use, improving livestock breeds to enhance their feed conversion efficiency, or planting trees in agricultural landscapes to reduce flood risks.

The issue of biotechnology use in agriculture is perhaps the most highly contested, with most of the focus on genetically modified organisms (GMOs). The use of GMOs has been limited to few crops, used mostly for fiber (cotton) and feed and oil (maize, soybean, canola) with limited use for direct human consumption (papaya, maize, canola). Furthermore, while adoption of GMOs on farm has been quite broad in the U.S., Canada, Brazil, Argentina, and South Africa, and in cotton in other major countries (India, China), its use in Europe and most of Africa has been limited or even practically banned. Most major national academies of science and international organizations have argued that it poses no new health risks compared to other sources of food, and there is evidence that GMOs have reduced the price of major agricultural commodities as well as the extent of GHG emissions (Barrows et al. 2014). There is also significant evidence that it has improved the well-being of poor farmers, especially in cotton production (Klümper and Qaim 2014; Qaim 2015). 
Nonetheless, significant concern about environmental and social effects of GMOs persists and there is ongoing debate on the application of the precautionary principle by opponents of the technology. Another source of concern is the large role of the private sector in the development of the technology and its control of intellectual property rights. But the heavy regulatory requirements associated with the development of GMOs has led to the concentration of the industry in the hands of a few major companies (Bennett et al. 2013). More recently however, the reduction of the cost of genome mapping and the introduction of new technologies like gene editing increase the capacity of a broader range of stakeholders to utilize and control modern biotechnology to provide effective and quick solutions to address the challenges of climate change.

The issue of which technologies to consider, and specifically whether biotechnologies should be included has been addressed in different ways under current applications of the CSA approach. To a large extent, the technologies and practices considered under CSA approaches are ones that governments have already included in their national agricultural plans, which often do not include biotechnology at present. Under the EC funded FAO CSA project, consultations with national policymakers and stakeholders including representatives from farmer's associations and other civil society groups have been held to identify a set of possible options for further detailed analysis. The World Bank/CCAFS profiles analyse a range of technologies and practices that are currently being practiced in the country or that are likely to be beneficial under projected climate change conditions, including from traditional as well as science based sources. They also provide a set of country specific criteria for identifying climate smartness of the technologies which also give information on the economic, environmental and social impacts of the technologies in that country. Ultimately, CSA neither mandates nor excludes the use of biotechnology or GMOs for any specific user of the approach, but it can provide a basis for helping potential users identify the risks and benefits of its use in addressing the challenges of achieving food security under climate change.

\section{Conclusion}

Climate smart agriculture is a relatively new concept which was launched in 2009 advocating for better integration of adaptation and mitigation actions in agriculture to capture synergies between them and to support sustainable agricultural development for food security under climate change. The rapid uptake of the concept after its launch indicates the tremendous demand for a framework to guide policy and technical interventions in agriculture that integrates the effects of change, the challenges of achieving sustainable agricultural development and the critical role of agriculture in attaining food security. At the same time, the widespread adoption of the CSA term prior to the development of a formal conceptual framing and 
methodology has lead to considerable variation in meanings applied to the term, as well as confusion and controversy.

The CSA concept has been reshaped through inputs and interactions of multiple stakeholders involved in developing and implementing the concept. At this point there is greater clarification on the definition of the concept and methodology for its application. However controversies over CSA remain. Most of these are related to the controversies in climate change and sustainable agricultural policies. In particular, the role of agricultural mitigation and its financing in developing countries, as well as the development and deployment of technologies for agricultural development are two key areas of continuing controversy in the respective policy circles. CSA does not attempt to provide a prescription to any user of the approach for resolving the controversies, but rather a tool to identify locally appropriate solutions to managing agriculture for sustainable development and food security under climate change. Ultimately the utility of the concept and its implementation will be judged by its effectiveness in integrating climate change responses into sustainable agricultural development actions on the ground.

\section{References}

Action Aid 2011 'Fiddling with carbon markets while Africa burns' Action Aid Johannesburg http://www.actionaid.org/publications/fiddling-soil-carbonmarkets-while-africa-burns

Barrows, Geoffrey, Steven Sexton, and David Zilberman. "Agricultural biotechnology: the promise and prospects of genetically modified crops." The Journal of Economic Perspectives 28, no. 1 (2014): 99-119.

Bennett, Alan B., Cecilia Chi-Ham, Geoffrey Barrows, Steven Sexton, and David Zilberman. "Agricultural biotechnology: economics, environment, ethics, and the future." Annual Review of Environment and Resources 38 (2013): 249-279.

Cooper, Mark. "The Economic and Institutional Foundations of the Paris Agreement on Climate Change: The Political Economy of Roadmaps to a Sustainable Electricity Future" Available at SSRN 2722880 (2016).

David Tilman, Kenneth G. Cassman, Pamela A. Matson, Rosamond Naylor, Stephen Polasky, (2002) Agricultural sustainability and intensive production practices. Nature 418 (6898):671-677

FAO 2009 Food Security and Agricultural Mitigation in Developing Countries: Options for Capturing Synergies FAO Rome http://www.fao.org/docrep/012/i1318e/i1318e00.pdf

FAO 2010. Climate-Smart Agriculture: Policies, Practices and Financing for Food Security, Adaptation and Mitigation. Rome, FAO.

FAO 2011 Climate Change Mitigation Finance for Smallholder Agriculture: A guide book to harvesting soil carbon sequestration benefits FAO Rome http://www.fao.org/docrep/015/i2485e/ i2485e00.pdf

FAO. (2013). Climate smart agriculture sourcebook. FAO Rome.

FAO 2016 State of Food and Agriculture Report "Climate change Agriculture and Food Security" FAO Rome http://www.fao.org/3/a-i6030e.pdf

Gupta, Joyeeta 2010 A history of international climate change policy Wiley Interdisciplinary Reviews: Climate Change Vol. 1 Issue 5 pp 621-763 
Hamrick K. and A. Goldstein 2016 "Raising Ambition: State of the Voluntary Carbon Markets 2016" Ecosystem Marketplace Washington DC http://www.forest-trends.org/documents/files/ doc_5242.pdf

Henry Neufeldt, Molly Jahn, Bruce M Campbell, John R Beddington, Fabrice DeClerck, Alessandro De Pinto, Jay Gulledge, Jonathan Hellin, Mario Herrero, Andy Jarvis, David LeZaks, Holger Meinke, Todd Rosenstock, Mary Scholes, Robert Scholes, Sonja Vermeulen, Eva Wollenberg, Robert Zougmoré, (2013) Beyond climate-smart agriculture: toward safe operating spaces for global food systems. Agriculture \& Food Security 2 (1):12

Huang, Jikun, Jun Yang, Siwa Msangi, Scott Rozelle, and Alfons Weersink. "Biofuels and the poor: Global impact pathways of biofuels on agricultural markets." Food Policy 37, no. 4 (2012): 439-451.

International Assessment of Agricultural Science, Knowledge and Technology for Development (IAASTD) 2009. Agriculture at a Crossroads Synthesis Report Island Press Washington DC

Klümper, Wilhelm, and Matin Qaim. "A meta-analysis of the impacts of genetically modified crops." PLoS One 9, no. 11 (2014): e111629

Lal, Rattan. "Soil carbon sequestration to mitigate climate change." Geoderma 123, no. 1 (2004): $1-22$.

Larson, A.M., Brockhaus, M., Sunderlin, W.D., Duchelle, A.E., Babon, A., Dokken, T., Pham, T.T., Resosudarmo, I. A. P., Selaya, G., Awono, A., Huynh T-B. "Land tenure and REDD+: the good, the bad and the ugly." Global Environmental Change 23, no. 3 (2013): 678-689.

Leach, M. and I. Scoones 2015 Political Ecologies of Carbon in Africa in Carbon Conflicts and Forest Landscapes in Africa in June 2015 https://www.routledge.com/products/9781138824836

Leslie Lipper, Philip Thornton, Bruce M. Campbell, Tobias Baedeker, Ademola Braimoh, Martin Bwalya, Patrick Caron, Andrea Cattaneo, Dennis Garrity, Kevin Henry, Ryan Hottle, Louise Jackson, Andrew Jarvis, Fred Kossam, Wendy Mann, Nancy McCarthy, Alexandre Meybeck, Henry Neufeldt, Tom Remington, Pham Thi Sen, Reuben Sessa, Reynolds Shula, Austin Tibu, Emmanuel F. Torquebiau, (2014) Climate-smart agriculture for food security. Nature Climate Change 4 (12): 1068-1072

McCarl, Bruce A., and Uwe A. Schneider. "The cost of greenhouse gas mitigation in US agriculture and forestry." Science 294, no. 21 (2001): 2481-82.

Paustian, Keith, Bruce Babcock, J. Hatfield, Rattan Lal, B. A. McCarl, S. McLaughlin, A. Mosier et al. "Agricultural mitigation of greenhouse gases: science and policy options." CAST (Council on Agricultural Science and Technology) Report 141 (2004): 2004.

P. L. Pingali, (2012) Green Revolution: Impacts, limits, and the path ahead. Proceedings of the National Academy of Sciences 109 (31):12302-12308

Post, Wilfred M., R. Cesar Izaurralde, Linda K. Mann, and Norman Bliss."Monitoring and verifying changes of organic carbon in soil." In Storing Carbon in Agricultural Soils: A MultiPurpose Environmental Strategy, pp. 73-99. Springer Netherlands, 2001.

Qaim, Matin. Genetically Modified Crops and Agricultural Development. Palgrave Macmillan, Basingstoke 2015.

Ringius, Lasse. "Soil carbon sequestration and the CDM: opportunities and challenges for Africa." Climatic change 54, no. 4 (2002): 471-495.

Scoones, Ian 'The politics of global assessments: the case of the International Assessment of Agricultural Knowledge, Science and Technology for Development (IAASTD)', Journal of Peasant Studies, (2009) 36: 3, 547-571.

P. Smith, D. Martino, Z. Cai, D. Gwary, H. Janzen, P. Kumar, B. McCarl, S. Ogle, F. O'Mara, C. Rice, B. Scholes, O. Sirotenko, M. Howden, T. McAllister, G. Pan, V. Romanenkov, U. Schneider, S. Towprayoon, M. Wattenbach, J. Smith, (2008) Greenhouse gas mitigation in agriculture. Philosophical Transactions of the Royal Society B: Biological Sciences 363 (1492):789-813 
Tan, Xiaomei. "Clean technology R\&D and innovation in emerging countries-experience from China." Energy Policy 38, no. 6 (2010): 2916-2926.

WCED, UN. "Our common future." World Commission on Environment and Development Oxford University Press (1987).

World Bank 2011 State and Trends of the Carbon Market 2011. World Bank Washington DC https://siteresources.worldbank.org/INTCARBONFINANCE/Resources/StateAndTrend_ LowRes.pdf

Zilberman, David. "The economics of sustainable development." American Journal of Agricultural Economics 96, no. 2 (2014): 385-396.

Zilberman, David, Scott Kaplan, Gal Hochman, and Deepak Rajagopal. "Political Economy of Biofuels." In The Impacts of Biofuels on the Economy, Environment, and Poverty, pp. 131-144. Springer New York, 2014.

Open Access This chapter is distributed under the terms of the Creative Commons AttributionNonCommercial-ShareAlike 3.0 IGO license (https://creativecommons.org/licenses/by-nc-sa/3.0/ igo/), which permits any noncommercial use, duplication, adaptation, distribution, and reproduction in any medium or format, as long as you give appropriate credit to the Food and Agriculture Organization of the United Nations (FAO), provide a link to the Creative Commons license and indicate if changes were made. If you remix, transform, or build upon this book or a part thereof, you must distribute your contributions under the same license as the original. Any dispute related to the use of the works of the FAO that cannot be settled amicably shall be submitted to arbitration pursuant to the UNCITRAL rules. The use of the FAO's name for any purpose other than for attribution, and the use of the FAO's logo, shall be subject to a separate written license agreement between the FAO and the user and is not authorized as part of this CC-IGO license. Note that the link provided above includes additional terms and conditions of the license.

The images or other third party material in this chapter are included in the chapter's Creative Commons license, unless indicated otherwise in a credit line to the material. If material is not included in the chapter's Creative Commons license and your intended use is not permitted by statutory regulation or exceeds the permitted use, you will need to obtain permission directly from the copyright holder.

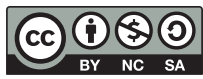

